\title{
Highly Pathogenic Avian Influenza A(H5N6) Virus Clade 2.3.4.4h in Wild Birds and Live Poultry Markets, Bangladesh
}

\author{
Jasmine C.M. Turner, Subrata Barman, Mohammed M. Feeroz, M. Kamrul Hasan, \\ Sharmin Akhtar, Trushar Jeevan, David Walker, John Franks, Patrick Seiler, Nabanita Mukherjee, \\ Lisa Kercher, Pamela McKenzie, Tommy Lam, Rabeh El-Shesheny, Richard J. Webby
}

Migratory birds play a major role in spreading influenza viruses over long distances. We report highly pathogenic avian influenza $\mathrm{A}(\mathrm{H} 5 \mathrm{~N} 6)$ viruses in migratory and resident ducks in Bangladesh. The viruses were genetically similar to viruses detected in wild birds in China and Mongolia, suggesting migration-associated dissemination of these zoonotic pathogens.

$\mathrm{H}$ ighly pathogenic avian influenza (HPAI) A(H5) viruses were identified in 1996 in a goose from Guangdong, China, and the evolution of the hemagglutinins (HAs) of these A/goose/Guangdong/1/96 (Gs/GD) lineage viruses has given rise to multiple genetically distinct phylogenetic clades (1). The emergence of HA clade 2.3.4.4 viruses was associated with several different virus subtypes, including H5N6 (2). As of March 2021, a total of 29 laboratory-confirmed human cases of $\mathrm{H} 5 \mathrm{~N} 6$ viruses have been reported from China, and 9 patients have died (3). Clade 2.3.4.4 H5N6 viruses have subsequently evolved, requiring further clade designations. Clade 2.3.4.4h viruses are found in China, Laos, and Vietnam (4). In December 2019 and January 2020, 2.3.4.4 H5N6 viruses were isolated from dead migratory whooper swans (Cygnus cygnus) and mute swans (Cygnus olor) in Xinjiang,

Author affiliations: St. Jude Children's Research Hospital, Memphis, Tennessee, USA (J.C.M. Turner, S. Barman, T. Jeevan, D. Walker, J. Franks, P. Seiler, N. Mukherjee, L. Kercher, P. McKenzie, R. El-Shesheny, R.J. Webby); Jahangirnagar University, Savar, Bangladesh (M.M. Feeroz, M.K. Hasan, S. Akhtar); The University of Hong Kong School of Public Health, Hong Kong, China (T. Lam); National Research Centre, Giza, Egypt (R. El-Shesheny)

DOI: https://doi.org/10.3201/eid2709.210819 western China (5). In April 2021, the same virus was detected in migratory birds in Mongolia (6).

In Bangladesh, HPAI A(H5) viruses have been in circulation since 2008; the predominant clades found are 2.2.2 and 2.3.2.1a. HPAI A(H5N6) clade 2.3.4.4b viruses were identified in domestic poultry in Bangladesh in $2016(7,8)$. Although the viruses were detected in live poultry markets (LPMs), they did not replace the H5N1 viruses in circulation, and as of April 2021, there have been no more reports of H5N6 virus detection $(9,10)$. We report a new introduction of clade 2.3.4.4.h viruses that are similar to viruses detected in China (Xinjiang) and Mongolia $(5,6)$, suggesting that migratory birds of the Central Asian flyway introduced this virus into Bangladesh.

\section{The Study}

Since 2015, our active surveillance in Bangladesh has been ongoing in both LPMs and Tanguar Haor, a wetlands area where local domestic ducks are reared and where birds winter during the migratory season (Appendix, Table 1, https://wwwnc.cdc.gov/EID/ article/27/9/21-0819-App1.pdf). We collected H5N6 virus-positive oropharyngeal and cloacal swabs from 2 apparently healthy wild birds in Baghmara, Tanguar Haor: a ferruginous duck on January 19, 2020, and a common pochard on January 20, 2020. We also obtained positive fecal samples from wild mallard ducks on January 26, 2020, in Puran Gao, Tanguar Haor. The next day, we obtained positive oropharyngeal and cloacal swabs from apparently healthy Khaki Campbell ducks located on various farms in Golabari, Tanguar Haor (Appendix Table 1). On February $18,2020, \approx 3$ weeks after detection of $\mathrm{H} 5 \mathrm{~N} 6$ virus in Tanguar Haor, an apparently healthy mallard duck 
located in a Dhaka LPM was also found to be infected with H5N6. Surveillance conducted on February 22, 2020, on various farms in Chitergao, Tanguar Haor, revealed an additional 24 more apparently healthy Khaki Campbell ducks infected with H5N6 virus. During our surveillance study, we identified a total of 40 domestic and wild birds infected with $\mathrm{H} 5 \mathrm{~N} 6$ virus clade 2.3.4.4h during January-February 2020 (Appendix Table 1).

We determined the complete genome sequences of the $40 \mathrm{HPAI} \mathrm{A}(\mathrm{H} 5 \mathrm{~N} 6)$ viruses. The sequence similarity between viruses was $99.4 \%-100 \%$. As a representative virus, A/Ferruginous duck/Bangladesh/42380/2020 (H5N6) had a high nucleotide identity $(99.6 \%-99.9 \%)$ to the HPAI A(H5N6) viruses of clade 2.3.4.4h from China (Xinjiang, January 2020) and Mongolia (April 2020) (Table).

An outbreak of $\mathrm{H} 5 \mathrm{~N} 6$ virus clade 2.3.4.4h in whooper swans in China (Xinjiang) and Mongolia in early 2020 suggested potential further distribution of these viruses across Asia, especially to areas where poultry is raised along the migration routes of wild birds. We combined genome sequences generated in this study with all sequences of H5N6 viruses available in GenBank and the GISAID database (11). Phylogenetic analysis confirmed that the Bangladeshi $\mathrm{A}(\mathrm{H} 5 \mathrm{~N} 6)$ isolates are of clade 2.3.4.4h and clustered with the recent HPAIV A(H5N6) isolates from whooper swans in Xinjiang, western China and in Mongolia (Figure 1, https:/ /wwwnc.cdc. gov/EID/article/27/9/21-0819-F1.htm). The time of most recent common ancestry for HPAI A(H5N6) viruses (Figure 2, https://wwwnc.cdc.gov/EID/ article/27/9/21-0819-F2.htm) suggests that the viruses from China, Mongolia, and Bangladesh share a common ancestor of unknown origin that emerged around mid-2019.

The phylogenetic clustering observed for the $\mathrm{H} 5$ gene was also conserved for the remaining 7 genes; the viruses from Bangladesh, China, and Mongolia were of the same genotype, with no evidence of reassortment (Appendix Figure). The A(H5N6) viruses from Bangladesh shared genetic features with their homologs from China, including an HA cleavage site, PLRERRRKR/G, which is characteristic of high pathogenicity in chickens (Appendix Table 2). We also found an amino acid deletion at position 133 in the HA protein (H3 numbering) in all our isolates, a feature common with clade 2.3.4.4.h isolated from humans (Appendix Table 2) and associated with alteration of the H5 HA receptor binding pocket (12). Deletions were also present in both neuraminidase (NA) (an 11-aa deletion in the stalk region) and nonstructural protein 1 (NS1) (deletion from residues 80-84; Appendix Table 2), which are associated with high pathogenicity in avian hosts (13). Postinfection ferret antisera raised to A/duck/Bangladesh/43127/2020 (H5N6) reacted to the World Health Organization's candidate clade 2.3.4.4h vaccine virus, A/ Guangdong/18SF020/2018 and, as expected, to all Bangladesh H5N6 viruses tested (Appendix Table 3).

Migratory birds are key in the evolution, maintenance, and spread of avian influenza viruses. We have previously identified viruses in LPMs after their detection in wild birds and domestic ducks in Tanguar Haor $(8,14,15)$. Similarly, detection of the H5N6 virus in an LPM after detection in Tanguar Haor highlights the continuum of migratory birds of the Central Asian flyway and domestic ducks in Tanguar Haor as vectors for viral movement at the wild bird-poultry

\begin{tabular}{|c|c|c|c|}
\hline Gene & GenBank accession no. & Virus & \% Identity \\
\hline \multirow[t]{2}{*}{ PB2 } & MT872369.1 & A/Whooper swan/Mongolia/25/2020 (H5N6) & 99.83 \\
\hline & MW108029.1† & A/duck/Hunan/1.12_YYGK74H3-OC/2018 (H5N6) & 98.65 \\
\hline \multirow[t]{2}{*}{ PB1 } & MT872369.1 & A/Whooper swan/Mongolia/25/2020 (H5N6) & 99.87 \\
\hline & MW104086.1 & A/chicken/Guangdong/7.20_DGCP022-O/2017 (H5N6) & 99.04 \\
\hline \multirow[t]{2}{*}{ PA } & EPI_ISL_418181 & A/Whooper swan/Xinjiang/13/2020 (A/H5N6) & 99.9 \\
\hline & EPI_ISL_340825 & A/Env/Guangdong/Jieyang/C18289059/2018(H5N6) & 99.5 \\
\hline \multirow[t]{2}{*}{$\mathrm{HA}$} & EPI_ISL_418175 & A/Whooper swan/Xinjiang/7/2020 (A/H5N6) & 99.8 \\
\hline & EPI_ISL_340844 & A/Env/Guangdong/C17285752/QY/2017 (H5N6) & 98.9 \\
\hline \multirow[t]{2}{*}{ NP } & MT872369.1 & A/Whooper swan/Mongolia/25/2020 (A/H5N6) & 99.65 \\
\hline & MW108029.1 & A/duck/Hunan/1.12_YYGK74H3-OC/2018 (H5N6) & 99.64 \\
\hline \multirow[t]{2}{*}{ NA } & EPI_ISL_418181 & A/Whooper swan/Xinjiang/13/2020 (A/H5N6) & 99.9 \\
\hline & $\mathrm{MW} 10 \overline{8} 138.1$ & A/duck/Hunan/11.30_YYGK63E3-OC/2017 (H5N6) & 99.36 \\
\hline \multirow[t]{2}{*}{ M } & MT872369.1 & A/Whooper swan/Mongolia/25/2020 (H5N6) & 99.6 \\
\hline & EPI ISL 340825 & A/Env/Guangdong/Jieyang/C18289059/2018 (H5N6) & 99.9 \\
\hline \multirow[t]{2}{*}{ NS } & EPI_ISL_418181 & A/Whooper swan/Xinjiang/13/2020 (A/H5N6) & 99.9 \\
\hline & $\mathrm{MW} 10 \overline{8} 029.1$ & A/duck/Hunan/1.12_YYGK74H3-OC/2018 (H5N6) & 99.29 \\
\hline
\end{tabular}

*HA, hemagglutinin; MP, matrix protein; NA, neuraminidase; NP, nucleoprotein; NS, nonstructural protein; PA, acidic polymerase; PB1, basic polymerase 1; PB2, basic polymerase 2 .

†Nearest virus homologs to A/Ferruginous duck/Bangladesh/42380/2020 (H5N6) excluding the H5N6 viruses from China (Xinjiang), and Mongolia. 
interface. We also detected a duck that was co-infected with A/duck/Bangladesh/44500/2020 (H10N7) and A/duck/Bangladesh/44500/2020 (H5N6), raising the possibility of reassortment and highlighting the potential effect of this genetic diversification.

\section{Conclusions}

We have identified HPAIV A(H5N6) viruses from migratory birds, domestic duck farms, and LPMs in Bangladesh at a similar time to their detection in China and Mongolia. The wider distribution of this group of viruses with documented zoonotic potential is cause for considerable public health concern. Monitoring for their establishment in South Central Asia must be intensified.

\section{Acknowledgments}

We thank the World Health Organization's Global Influenza Surveillance and Response System for viral antigens used in antigenic analyses.

This work was funded by the National Institute of Allergy and Infectious Diseases, National Institutes of Health (grant no. HHSN272201400006C) and ALSAC.

\section{About the Author}

Ms. Turner is a lead researcher in the department of infectious diseases at St. Jude Children's Research Hospital, Memphis, Tennessee, USA. Her major research interests are influenza virus ecology and evolution, influenza virus pathogenicity, and diagnosis and surveillance of influenza A viruses and their role in the emergence of new pandemic strains for humans and lower animals.

\section{References}

1. Smith GJ, Donis RO; World Health Organization/World Organisation for Animal Health/Food and Agriculture Organization (WHO/OIE/FAO) H5 Evolution Working Group. Nomenclature updates resulting from the evolution of avian influenza $\mathrm{A}(\mathrm{H} 5)$ virus clades 2.1.3.2a, 2.2.1, and 2.3.4 during 2013-2014. Influenza Other Respir Viruses. 2015;9:271-6. https:// doi.org/10.1111/irv.12324

2. Yang L, Zhu W, Li X, Bo H, Zhang Y, Zou S, et al. Genesis and dissemination of highly pathogenic H5N6 avian influenza viruses. J Virol. 2017;91:91. https:/ / doi.org/ 10.1128/JVI.02199-16

3. World Health Organization. Human infections with avian influenza A(H5N6) virus -China. 2020 [cited 2020 Nov 10]. https://wwwwhoint/docs/default-source/wprodocuments/emergency/surveillance/avian-influenza/ ai-20201002pdf?sfvrsn=223ca73f_66

4. World Health Organization. Antigenic and genetic characteristics of zoonotic influenza viruses and candidate vaccine viruses developed for potential use in human vaccines. 2021 [cited 2021 Mar 26]. https:/ / www.who.int/ influenza/vaccines/virus/202103_zoonotic_vaccinevirus update.pdf

5. Li Y, Li M, Li Y, Tian J, Bai X, Yang C, et al. Outbreaks of highly pathogenic avian influenza (H5N6) virus subclade 2.3.4.4h in swans, Xinjiang, Western China, 2020. Emerg Infect Dis. 2020;26:2956-60. https:/ / doi.org/10.3201/ eid2612.201201

6. Jeong S, Otgontogtokh N, Lee DH, Davganyam B, Lee SH, Cho AY, et al. Highly pathogenic avian influenza clade 2.3.4.4 subtype H5N6 viruses isolated from wild whooper swans, Mongolia, 2020. Emerg Infect Dis. 2021;27:1181-3. https:// doi.org/10.3201/eid2704.203859

7. Yang G, Chowdury S, Hodges E, Rahman MZ, Jang Y, Hossain ME, et al. Detection of highly pathogenic avian influenza $\mathrm{A}(\mathrm{H} 5 \mathrm{~N} 6)$ viruses in waterfowl in Bangladesh. Virology. 2019;534:36-44. https://doi.org/10.1016/ j.virol.2019.05.011

8. Barman S, Turner JCM, Hasan MK, Akhtar S, El-Shesheny R, Franks J, et al. Continuing evolution of highly pathogenic $\mathrm{H} 5 \mathrm{~N} 1$ viruses in Bangladeshi live poultry markets. Emerg Microbes Infect. 2019;8:650-61. https:/ / doi.org/10.1080/ 22221751.2019.1605845

9. Kwon J-H, Lee D-H, Criado MF, Killmaster L, Ali MZ, Giasuddin M, et al. Genetic evolution and transmission dynamics of clade 2.3.2.1a highly pathogenic avian influenza A/H5N1 viruses in Bangladesh. Virus Evol. 2020;6:veaa046. https://doi.org/10.1093/ve/veaa046

10. Islam K, Ahsan MM, Chakma S, Penjor K, Barua M, Jalal MS, et al. An assessment on potential risk pathways for the incursion of highly pathogenic avian influenza virus in backyard poultry farm in Bangladesh. Vet World. 2020;13:210411. https:/ / doi.org/10.14202/vetworld.2020.2104-2111

11. Shu Y, McCauley J. GISAID: Global initiative on sharing all influenza data - from vision to reality. Euro Surveill. 2017; 22:22. https:/ / doi.org/10.2807/1560-7917.ES.2017.22.13.30494

12. Watanabe $Y$, Ibrahim MS, Ellakany HF, Kawashita N, Mizuike R, Hiramatsu H, et al. Acquisition of human-type receptor binding specificity by new $\mathrm{H} 5 \mathrm{~N} 1$ influenza virus sublineages during their emergence in birds in Egypt. PLoS Pathog. 2011;7:e1002068. https://doi.org/10.1371/journal. ppat.1002068

13. Cui Y, Li Y, Li M, Zhao L, Wang D, Tian J, et al. Evolution and extensive reassortment of $\mathrm{H} 5$ influenza viruses isolated from wild birds in China over the past decade. Emerg Microbes Infect. 2020;9:1793-803. https:/ / doi.org/10.1080/ 22221751.2020.1797542

14. El-Shesheny R, Feeroz MM, Krauss S, Vogel P, McKenzie P, Webby RJ, et al. Replication and pathogenic potential of influenza A virus subtypes H3, H7, and H15 from freerange ducks in Bangladesh in mammals. Emerg Microbes Infect. 2018;7:1-13. https:// doi.org/10.1038/s 41426-018-0072-7

15. El-Shesheny R, Barman S, Feeroz MM, Hasan MK, Jones-Engel L, Franks J, et al. Genesis of influenza A(H5N8) viruses. Emerg Infect Dis. 2017;23:1368-71. https:/ / doi.org/ 10.3201/eid2308.170143

Address for correspondence: Richard J. Webby, Department of Infectious Diseases, MS 330, St. Jude Children's Research Hospital, 262 Danny Thomas Pl, Memphis, TN 38105-3678, USA; email: richard.webby@stjude.org 